\title{
Impactos ambientais oriundos do crescimento urbano/demográfico: um estudo no bairro da Pedreira, Belém/PA
}

Com a intensificação dos processos industriais a partir o século XVIII, a população urbana cresceu de forma significativa, provocando graus de urbanização que podem chegar aos $90 \%$ no Brasil. O avanço da urbanização acelerada e desordenada, a expansão das metrópoles e o uso irregular do solo implicaram em diversos impactos ao meio ambiente - tanto natural quanto construído - e transtornos a sociedade. Diante disso, o presente estudo apresenta como objetivo analisar o crescimento do bairro da Pedreira, situado na cidade de Belém/PA, articulando problemas do meio ambiente urbano com a evolução histórica do bairro. A fim relacionar essas questões foram feitas, primeiramente, revisões bibliográficas, para análise das consequências urbanas e ambientais presentes no bairro; realizouse também pesquisa documental, utilizando cenas de sensoriamento remoto disponíveis no site do United States Geological Survey (USGS) da plataforma Global Visualization Viewer (GloVis), assim como imagens satélites fornecidos pelo Google Earth. As cenas geradas foram tratadas no ArcGIS, para visualização mais contrastante das áreas verdes e urbanizadas. Por fim, utilizou-se a pesquisa exploratória com observações in loco para reforçar os dados sobre os impactos ambientais decorrentes da urbanização da Pedreira. Este estudo espera contribuir para demonstrar como o processo de urbanização acelerado está relacionado com a qualidade ambiental do referido bairro.

Palavras-chave: Urbanização; Impactos ambientais; Meio ambiente urbano; Cidades.

\section{Environmental impacts from urban/demographic growth: a case study in the neighborhood of Pedreira, Belém/PA}

\begin{abstract}
With the intensification of industrial processes since the 18th century, the urban population has grown significantly, causing degrees of urbanization that can reach $90 \%$ in Brazil. The advance of accelerated and disordered urbanization, the expansion of the metropolises and the irregular use of the soil implied several impacts on the environment - both natural and built - and disturbances to society. Therefore, this study aims to analyze the growth of the neighborhood of Pedreira, located in the city of Belém/PA, articulating problems of the urban environment with the historical evolution of the neighborhood. In order to relate these issues, bibliographic reviews were first made to analyze the urban and environ-mental consequences present in the neighborhood; documentary research was also carried out, using remote sensing scenes available on the United States Geological Survey (USGS) website of the Global Visualization Viewer (GloVis) platform, as well as satellite images provided by Google Earth. The gene-rated scenes were treated and ArcGIS, for a more contrasting view of green and urbanized areas. Fi-nally, exploratory research with on-site observations was used to reinforce the data on the environ-mental impacts resulting from the urbanization of Pedreira. This study hopes to contribute to demons-trate how the accelerated urbanization process is related to the environmental quality of that neighborhood.
\end{abstract}

Keywords: Urbanization; Environmental impacts; Environment; Cities.

Topic: Desenvolvimento, Sustentabilidade e Meio Ambiente

Reviewed anonymously in the process of blind peer
Received: 04/12/2020

Approved: 21/12/2020
Leonardo Seabra Furtado (it)

Universidade da Amazônia, Brasil

http://lattes.cnpq.br/1121632168340477

http://orcid.org/0000-0001-8239-1348

leofurtado99@hotmail.com

Lucas Renan de Moraes Alves (D)

Universidade da Amazônia, Brasil

http://orcid.org/0000-0002-4212-6432

alvesbio07@gmail.com

Ana Beatriz Fernandes de Macedo (iD

Universidade da Amazônia, Brasil

http://lattes.cnpq.br/1754719466494278

http://orcid.org/0000-0002-4357-1001

anabeatrizfmacedo@gmail.com

\author{
Álvaro José de Almeida Pinto (iD \\ Universidade da Amazônia, Brasil \\ http://lattes.cnpq.br/9982946507934692 \\ http://orcid.org/0000-0002-7440-0053 \\ alvarojosealmeidap@gmail.com \\ Helena Lucia Zagury Tourinho (iD) \\ Universidade da Amazônia, Brasil \\ http://lattes.cnpq.br/5283117460253337 \\ http://orcid.org/0000-0001-7588-1680 \\ helenazt@uol.com.br \\ Roberta Dannyele Oliveira Raiol \\ Universidade da Amazônia, Brasil \\ http://lattes.cnpq.br/4546929979755221 \\ http://orcid.org/0000-0002-7552-7988 \\ raiol06@gmail.com
}

Referencing this:

FURTADO, L. S.; ALVES, L. R. M.; MACEDO, A. B. F.; PINTO, Á. J. A.; TOURINHO, H. L. Z.; RAIL, R. D. O.. Impactos ambientais oriundos do crescimento urbano/demográfico: um estudo no bairro da Pedreira, Belém/PA. Revista Ibero Americana de Ciências Ambientais, v.11, n.7, p.484-500, 2020. DOI: http://doi.org/10.6008/CBPC21796858.2020 .007 .0039 


\section{INTRODUÇÃO}

Silva et al. (2014) relatam que as consequências geradas pela urbanização são latentes e presentes na realidade dos habitantes das cidades - citando-se o acúmulo de lixo, as poluições sonora, da água e do ar, a perda de biodiversidade, dentre outras (COIMBRA et al., 2019). Os impasses causados pelas deficiências urbanísticas atravessam a dimensão ambiental e atingem, também, a área social, gerando problemas tais como a violência, os desequilíbrios na distribuição de renda e a segregação socioespacial. Igualmente, a atração dos grandes centros urbanos acarreta a imigração de pessoas, resultando em excessiva competição por espaço (SILVA et al., 2014).

As grandes cidades são como um organismo vivo e doente, que drena recursos - independente de ordem natural, construída ou humana - e é capaz de tornar espaços densamente ocupados ao lado de outros com forte êxodo demográfico, decadentes e desarticulados, transformando certas localidades em desertos demográficos, ao mesmo passo da formação de novas cidades (SANTOS, 2005; MINC, 2002).

Na Amazônia, o surgimento e crescimento populacional nas cidades, inicialmente, decorreu de relações mercantis como, a exploração das drogas do sertão e a extração de látex, atraindo milhares de habitantes da zona rural que procuravam melhorias das suas condições de vida nos centros urbanos (COSTA et al., 2019). Para autores, como Trindade Júnior (2015), a exploração econômica e a urbanização regional, foram intensificadas e aceleradas a partir dos anos 1960, impulsionadas pela abertura de rodovias de integração e pelos incentivos fiscais e creditícios à implantação de empreendimentos envolvidos com a extração e o beneficiamento de recursos naturais. Com isso, observou-se uma rápida transformação do espaço urbano e a geração de impactos não somente sociais como ambientais.

Ao tentar conceituar o termo meio ambiente esbarra-se em uma dificuldade: a grande quantidade de acepções disponíveis na literatura. Isso porque as definições surgem conforme o campo de conhecimento e à medida em que se desenvolvem e se alteram as relações entre homem-natureza. Partindo desse princípio, novas concepções são formuladas e se constroem subsídios para a compreensão e entendimento do termo.

Atualmente, no Brasil, o conceito mais amplamente utilizado por todas as áreas do saber é o instituído pela Política Nacional do Meio Ambiente (PNMA). O instrumento - em seu art. $3^{\circ}$, inciso I - se refere ao meio ambiente como "um conjunto de condições, leis, influências e interações de ordem física, química e biológica, que permite, abriga e rege a vida em todas as suas formas" (BRASIL, 1981).

Quando se articulam o meio ambiente e meio urbano, nota-se que a crescente urbanização, a industrialização acelerada, os modos de vida e hábitos das pessoas que vivem em cidades podem se tornar adversos ao meio natural, colocando-o em risco. A ameaça ao meio natural, por sua vez, desencadeia outros problemas de ordem urbana para a população moradora, afetando o bem-estar, gerando estresse, além de um conjunto disfunções promovidas por diversos tipos de poluição, tanto do meio biótico, quanto do abiótico (GOMES et al., 2004).

Observando a importância ecológica e psicológica do meio ambiente para a população urbana, a qualidade e a manutenção ambiental são garantidas por lei. 0 artigo 225 da Constituição Federal (BRASIL, 
1988) afirma que: "Todos têm direito ao meio ambiente ecologicamente equilibrado, bem de uso comum do povo e essencial à sadia qualidade de vida, impondo-se ao poder público e à coletividade o dever de defendêlo e preservá-lo para as presentes e futuras gerações." A manutenção e conservação do espaço, portanto, é garantida por lei e complementada pela responsabilidade civil com o meio ambiente, mediante a conscientização da necessidade de restruturação da qualidade do mesmo (GOMES et al., 2004).

No quesito da qualidade ambiental urbana, os problemas relativos à urbanização desenfreada se agravaram, em países considerados subdesenvolvidos, na medida em que as cidades avançavam e "desenvolviam-se". Com avanço desordenado da urbanização, grande parcela da população constrói residências de maneira irregular em áreas de risco, criando obstáculos para inserção de projetos ambientais. A execução desses projetos ambientais são fundamentais para aproximar e conscientizar a população que mais necessita de conhecimento sobre a importância dos espaços "verdes" e acerca de cuidado e controle com o meio ambiente, pois esses espaços protegem fatores naturais e asseguram a saúde dos habitantes (KRZYSCZAK, 2016).

Sem o sucesso da implantação das políticas de educação ambiental, a sociedade fica à mercê da ambição capitalista e sujeita as definições do mercado imobiliário para o uso e ocupação do solo urbano. Consequentemente, os espaços verdes ficam atrelados à visão conservadora que o enxerga como algo estético, em que a natureza é utilizada apenas para o embelezamento ou como fonte de recursos, e negligência o papel que ela desempenha na manutenção e estruturação da cidade (GOMES et al., 2004). 0 enforque meramente estético dos espaços verdes, ressalte-se, era comum até o início da contemporaneidade. Várias cidades possuíam, nessa época, quantidades expressivas de áreas livres com a finalidade de embelezamento, e, obedeciam, especialmente, à arquitetura romântica e eclética (LOBODA et al., 2005).

No entanto, no final século XIX, atribui-se a esses espaços a aplicação utilitária por meio dos ideais modernistas, principalmente, em zonas urbanas muito povoadas. Com o intuito de estreitar a relação entre cidade e natureza (LOBODA et al., 2005), a vegetação urbana adquire outras funções muito além da estética, transpondo a barreira biológica e atingindo o plano psicológico humano.

Segundo Ribeiro et al. (2015), a retirada da cobertura vegetal urbana interfere diretamente nos microclimas, na biodiversidade e no bem-estar da sociedade. Com o declínio de áreas verdes no ambiente urbano, portanto, os problemas ambientais começam a afetar os habitantes. As poucas áreas verdes existentes tornam-se referências contra o avanço descontrolado da urbanização, visto que a cidade é composta por um conjunto de sistemas e possuem funções que se entrelaçam com o objetivo de melhorar a prática de vida local (LLARDENT, 1982).

A partir disso, entende-se que a relação entre do espaço urbano e natureza é fundamental para a promoção do conforto ambiental e do bem-estar compartilhado.

A crescente urbanização das cidades gerou a preocupação de todas as áreas do saber que trabalham com o meio ambiente, visto que os profissionais perceberam que o rápido avanço da urbanização, sobretudo 
no século XX, intensificava a transformação do meio natural, degradando-o, modificando o padrão de vida dos habitantes (GOMES et al., 2004).

O avanço urbano desordenado e sem planejamento sobre o meio natural, se não for contido, gerará prejuízos imprevisíveis para a sociedade. Segundo Mazzeto (2014), a humanidade é culpada pela degradação do meio ambiente físico e social e enfrentará os efeitos causados pelo crescimento populacional urbano desenfreado.

Com $84,72 \%$ da população morando nos centros urbanos (IBGE, 2016), os impactos ambientais causados pela supressão da vegetação, acúmulo de lixo, poluição sonora, visual e outros efeitos negativos só aumentam engendrando situações cada vez mais complexas e forçando as novas sociedades a se adaptarem (MENDONÇA et al., 2002). Gouveia (1999), por exemplo, ao constatar que há uma urbanização sem precedentes na história mundial, chama atenção que os seus desdobramentos - sejam físicos, químicos, sociais, econômicos, e, sobretudo, ambientais - têm provocado um importante impacto na saúde da população.

Para entender as consequências que a urbanização descontrolada causa à cidade é preciso analisar a história do local. Para Santos (1977), faz-se necessário saber se o centro urbano possuía estrutura urbanística pré-existente ou se o processo inicial de urbanização ocorreu de forma inesperada e pujante no local.

O descontrole da urbanização origina variadas consequências, destaca-se principalmente a temática do lixo, a falta de áreas verdes, o congestionamento de veículos, o aumento da acidez da chuva, formação de "ilhas de calor", a impermeabilização do solo urbano, as poluições sonora, visual e do ar (SILVA et al., 2014). Tais problemas não envolvem apenas as questões ambientais, circundam também a área social, acarretando problemas como a violência, o desequilíbrio na distribuição da renda e desigualdade socioespacial, evidenciando a realidade calamitosa das grandes cidades.

A falta de planejamento urbanístico agrava, ainda mais esse quadro. A atratividade dos grandes centros urbanos desloca pessoas mais pobres na direção deles, em busca de melhor qualidade de vida. No entanto, a competição por espaço e pelas oportunidades de trabalho aumenta a taxa de desemprego, de pessoas sem domicílio fixo ou que vivem em situação de vulnerabilidade, se submetendo a moradias situadas em áreas de risco (VARGAS, 2001).

Em virtude do elevado grau de urbanização e do caráter desordenado que esse processo vem assumindo na maioria das cidades da Amazônia, o presente estudo teve como objetivo geral, investigar os impactos dessa dinâmica no meio ambiente construído de um bairro de uma grande metrópole, no caso, o Bairro da Pedreira, localizado em Belém - a principal metrópole da Amazônia Oriental.

O trabalho está estruturado em quatro partes além dessa introdução. Inicialmente é apresentada a metodologia utilizada. A partir daí são analisados aspectos da expansão urbana no Brasil, Amazônia e Belém, de modo a contextualizar o processo urbano no bairro estudado. Posteriormente, são expostos os resultados da pesquisa empírica, demonstrando a relação entre o processo urbano e as transformações no meio ambiente do bairro da Pedreira. Finalmente, são apresentadas as principais conclusões do estudo. 


\section{METODOLOGIA}

Os meios utilizados para investigação são análises bibliográficas e pesquisa documental com cenas de sensoriamento remoto disponíveis no site do United States Geological Survey (USGS) da plataforma Global Visualization Viewer (GloVis), assim como Google Earth, a fim de relacionar o crescimento urbano e a supressão da vegetação dentro da cidade e do bairro descrito. As imagens geradas pelo GloVis foram tratadas no Arcgis, para identificação das áreas urbanizadas, solo exposto e vegetação. 0 estudo dentro do bairro se destinou por meio de pesquisa exploratória a partir de observações in loco registradas por meio de séries fotográficas, de sua conformação e dos principais impactos ocorridos na área a partir da ação antrópica, como impermeabilização do solo, acúmulo de lixo, poluição visual, sonora e ausência de áreas verdes significativas.

\section{Expansão urbana no Brasil}

A urbanização consiste na movimentação da população rural para as áreas urbanas, possibilitando a expansão da participação percentual da população urbana em relação a população total, tendo como causa o aumento paulatino de pessoas que buscam, na cidade, por melhores condições de vida, emprego e educação (PAWAN, 2016).

Prescrita como rápida transformação na sociedade humana, a urbanização não se trata apenas de um fenômeno moderno, mas da análise que parte, predominantemente, de padrões de culturas aldeãs formados há milhões de anos. Com o início da Revolução Industrial, na metade século XVIII, o crescimento populacional das cidades é deflagrado. A emigração da população rural para os centros urbanos e industriais provocou inchaço demográfico, acarretando a formação e a ampliação das metrópoles de todo o mundo e, por conseguinte, o surgimento de novas cidades (SPOSITO, 1988).

O IBGE (2001) classifica as áreas urbanas e rurais, respectivamente, como: "aquelas caracterizadas por construções, arruamentos e intensa ocupação humana; e aquelas que possuem um conjunto de edificações adjacentes ( $50 \mathrm{~m}$ ou mais de distância entre si) e com características de permanência, situado em área legalmente definida como rural". Compreendida por uma gama de objetos técnicos, redes viárias, prédios, praças, parques e outros, as cidades partem de uma ideologia moderna a qual busca interpretar mudanças no espaço-tempo das sociedades (CARLOS, 2001).

No Brasil, o processo de urbanização foi impulsionado no século $\mathrm{XX}$, com a queda da produção do café, a libertação dos escravos e a Proclamação da República. O poder público inicia as reformas urbanas investindo em melhorias de infraestrutura e condições físicas para a instalação indústrias, elevando o índice de urbanização para 68,86\% em 1980 (Santos, 2005). Nesse contexto, as cidades brasileiras conheceram as primeiras reformas urbanas, metrópoles como Belém, Manaus, Porto Alegre, Curitiba, Recife, São Paulo e Rio de Janeiro iniciaram um processo de reestruturação que se daria pelo embelezamento paisagístico, saneamento ambiental e segregação territorial (MARICATO, 2001; SANTOS, 2005). 
A industrialização no Brasil, embora tardia, ocorreu de forma acelerada. Em 1940, a maior parte da população brasileira se concentrava na zona rural, ao passo que os centros urbanos obtinham uma quantidade percentual inferior de pessoas (Figura 1) (IBGE, 2007).

A intensificação do desenvolvimento industrial na cidade, a mecanização e a concentração fundiária no campo, intensificadas a partir da segunda metade do século $X X$, estimulou a emigração de pessoas do campo para a cidade, fazendo com que o crescimento urbano ultrapassasse ao rural no período entre 19601970. Em 1970, a expansão demográfica urbana registra, pela primeira vez, a população urbana superior a rural, com taxa de 55,9\% de urbanização, repercutindo uma tendência não somente nacional, mas mundial (Figura 1) (Brito et al., 2018).

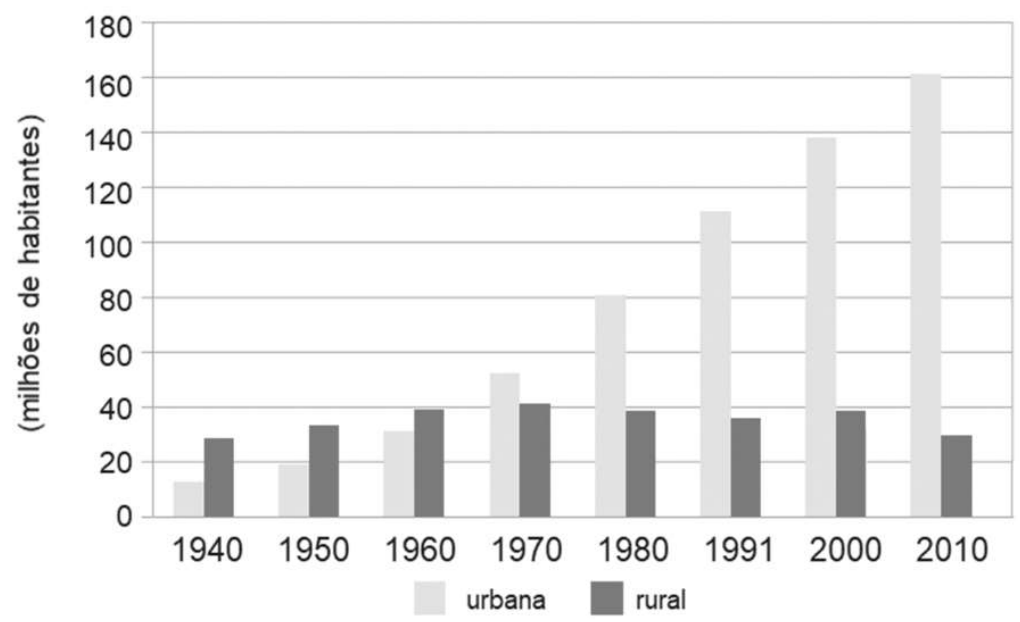

Figura 1 - Brasil: População, segundo a situação do domicílio, 1940 a 2010. Fonte: Instituto Brasileiro de Geografia e Estatística - IBGE

Esse aumento no crescimento urbano se consolidou na década de 1980, quando o êxodo levou 12.489.278 habitantes (30\% da população do campo) para as cidades (ALVES et al., 2011). A transferência vigorosa de indivíduos do campo para a cidade provocou graus de urbanização que podem chegar aos $90 \%$ no Brasil, superando os países desenvolvidos. Ultrapassando 18.782 .891 habitantes, a população na segunda metade do século XX atingiu 137.697.736 habitantes um crescimento de 7,33 vezes, um acréscimo de 2.378.291 habitantes por ano (BRITO et al., 2018).

\section{Urbanização na Amazônia}

Durante o século XIX, a ocupação na Amazônia foi gradativamente incentivada pela exploração das drogas do sertão e, posteriormente, pela produção da borracha. Os vilarejos localizados no delta do Rio Amazonas e no litoral, foram as primeiras manifestações da urbanização na região, que tinham a função de entrepostos comerciais utilizados para abastecer e escoar a produção extrativa primeiro de especiarias e depois gomífera. Após a Segunda Guerra Mundial, pequenos agricultores motivados pelo êxodo rural seguem em direção as grandes cidades, onde se estabelecem. Isso ocasiona o crescimento da população nas cidades e provoca uma urbanização, muitas vezes desorganizada. 
Até então, as cidades que surgiam na Amazônia eram fruto da urbanização tradicional ${ }^{1}$, vinculadas ao padrão organizacional denominado de rio - várzea - floresta, pois estavam intimamente ligadas à floresta por meio do extrativismo e aos rios que além de serem fonte de alimento, também formavam uma grande rede dendrítica de transporte (LOMBA et al., 2013).

O processo de urbanização na Amazônia foi intensificado por meio das intervenções estatais na década de 1960, com a abertura de estradas, a implementação de programas de colonização oficial e a concessão de um conjunto de incentivos governamentais para a implantação de grandes projetos econômicos na região. Como exemplos desses programas tem-se: o Programa de Polos Agropecuários e Agrominerais; Programa Grande Carajás (PCG); e a Zona Franca de Manaus (SUFRAMA). O incremento de infraestruturas e sistemas rodoviários, associado a instalação de empreendimentos econômicos possibilitaram a atração e o deslocamento de grande quantidade de pessoas para a região e para as cidades (RIBEIRO, 1996). A partir daí, verifica-se uma mudança no padrão de ocupação, inserindo novas formas de estrutura urbana (TOURINHO, 2011), agora obedecendo, também, a tipologia estrada - terra-firme - subsolo. A urbanização atrelada à necessidade de dar suporte e instalar infraestrutura aos profissionais qualificados e trabalhadores (permanentes e temporários) relacionados aos projetos de grande escala implantados na região dá origem a um conjunto de cidades planejadas na região (COSTA et al., 2019).

Concomitantemente, sobretudo na Amazônia oriental, e mais especificadamente no Estado do Pará, a urbanização foi estimulada mediante frentes extrativistas, minerais e vegetais. Cidades como Santarém e Marabá, ocupadas inicialmente pela exploração das drogas do sertão e pela extração da borracha, respectivamente, vivenciaram novos processos urbanos atraindo imigrantes (TRINDADE JÚNIOR, 2012).

A inserção de grandes projetos como o Projeto Jari, Almeirim (1968); Usina Hidrelétrica de Tucuruí, Tucuruí (1974/75); Projeto Trombetas, Oriximiná (1979); Projeto Carajás, Parauapebas (1985) e Projeto Albrás/Alunorte, Barcarena (1985/86), também beneficiaram e atraíram população para diversas localidades ao entorno. Esse processo foi acompanhado, de um lado da construção, em áreas sem ocupação urbana, de cidades planejadas (new towns ou company towns) para abrigar os trabalhadores mais qualificados. De outro lado, pela formação e/ou crescimento das periferias urbanas de cidades pré-existentes.

A lógica urbana amazônica é construída, principalmente, pela exploração de recursos e migração induzida pelo Estado, estimulando um crescimento geométrico populacional superior ao do Brasil, com taxas de 4,3\% a.a. entre 1970 e 1980. Posteriormente, essa taxa foi reduzindo, porém permaneceu acima da nacional.

Na capital Belém, o impacto causado pela inserção de novos projetos no interior do estado foi percebido, a partir do momento que se verifica uma queda da participação da capital e metrópole no crescimento econômico e demográfico paraense, um fenômeno chamado por Milton Santos de "involução metropolitana" (TRINDADE JÚNIOR, 2015).

\footnotetext{
${ }^{1}$ Segundo Trindade Júnior et al. (2008) enquadram-se como cidades tradicionais as estruturas urbanas antigas, mas que foram submetidas a transformações contemporâneas, oriundas de impactos sociais, culturais e ambientais, associadas aos novos modelos de produção e inovações tecnológicas na região.
} 


\section{A urbanização em Belém - PA}

Tendo os corpos d'água servido de base para a construção da cidade e para o escoamento da produção regional, Belém foi implantada, pelos colonizadores portugueses, na confluência do Rio Guamá com a Baía do Guajará, em um sítio estrategicamente escolhido para atender necessidades de defesa e controle territorial (PENTEADO, 1968). Fruto da urbanização tradicional, assim como várias outras cidades amazônicas, Belém apresentou, em sua configuração inicial, características excepcionalmente periféricas, evoluindo posteriormente, como consequência da penetração citadina no continente (MOREIRA, 1966).

Durante os anos de 1870 a 1910, a economia gomífera estabeleceu o processo de modernização da cidade. "Belém das bananeiras", como era conhecida anteriormente, adquiriu o slogan de "Belém: cidade das mangueiras", em razão dos processos de intervenções paisagísticas realizadas por Lemos no período da Belle Époque amazônica (SOARES, 2008). A riqueza produzida pela borracha atraiu milhares de imigrantes europeus, além de estimular a emigração de grande quantidade de nordestinos para a Amazônia.

O intendente da época, Antônio Lemos, objetivava modernizar Belém nos moldes de Paris, por meio da arborização nas ruas, e implantação de infraestruturas urbanas, como o sistema pioneiro no Brasil de iluminação e de bondes elétricos, a construção monumentos e a abertura de grandes boulevares. Sua visão foi considerada inovadora, e resultou em uma série de obras de embelezamento e higienização que promoveram a reurbanização da capital Belém.

Alavancada pela economia da borracha, a expansão urbana da época, a despeito dos projetos de ampliação da cidade, fez surgir grandes manchas urbanas periféricas, com paisagens que contrastavam com o centro remodelado. Com o declínio da produção de borracha, o extrativismo na mata é interrompido e algumas cidades interioranas começam a esvaziar-se, de forma a gerar um êxodo rural e o crescimento das cidades mais importantes (KAMPEL et al., 2001).

Durante a Segunda Guerra Mundial (1936-1945), Belém revive o ciclo da borracha, estimulado pelo aumento da demanda internacional por esse produto. Com o auxílio dos presidentes Getúlio Vargas e Franklin Delano Roosevelt, Brasil e Estados Unidos, firmaram o acordo de Washington, parceria que garantia a implementação de um conjunto de infraestruturas em troca de fornecimento de látex para abastecimento do governo norte americano (DIAS et al., 2007). É fruto desse acordo a construção dos primeiros diques contra a força das marés instalados no litoral belenense, assim como a instalação de sistema de saneamento básico e dos telégrafos.

Belém deixava de lado a visão francesa de progresso e desenvolvimento atrelada aos bondes elétricos, aos trilhos e palacetes e se associava a perspectiva americana de transporte urbano por ônibus zepelins, em pistas de asfalto cercadas por arranha céus (CHAVES, 2016). As intervenções urbanas voltadas para a circulação em veículos automotores viriam a ser fortalecidas após Juscelino Kubistchek de Oliveira (1956-1961), por meio de seus planos de desenvolvimento, criar a rodovia Belém-Brasília, o que intensificou a ocupação urbana e promoveu o surgimento de novos municípios (DIAS et al., 2007).

Cardoso et al. (2015) descrevem que, a partir da década de 1960, regiões como o Marajó e o baixo Tocantins, que não foram beneficiadas pela inserção de grandes projetos econômicos e infraestrutura 
passaram por processo de estagnação. Na busca por melhores condições de vida e oportunidades, parte da população de baixa renda destas regiões emigrou para Belém, ocupando áreas de várzeas, baixadas suscetíveis a inundação ou cidades vizinhas que compõe a Região Metropolitana de Belém (RMB) (Figura 2).

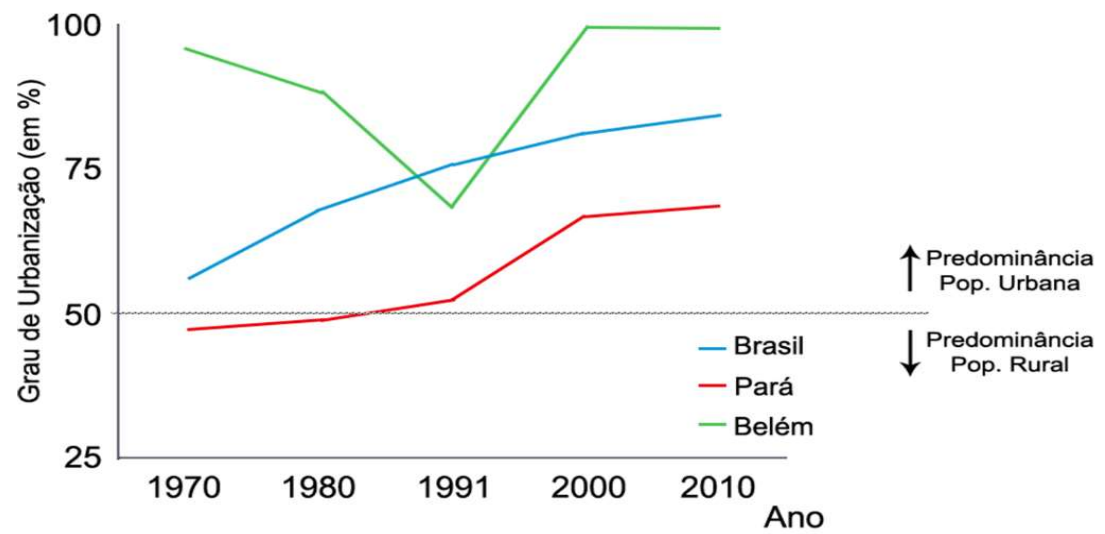

Figura 2 - Grau de urbanização, Brasil, Pará e Belém entre 1970 e 2010. Fonte: Cardoso et al., (2015), Belém: transformações na ordem urbana.

\section{Bairro da Pedreira: surgimento e formação}

O bairro da Pedreira - inicialmente chamado de Pedreira do Guamá em função de pedras que existiam na área - tem sua origem datada do final do século XIX e início do século XX e relacionada à implantação, pelo intendente Antônio Lemos do projeto de expansão urbana (Figura 3), sendo previsto no projeto rede de esgotos, iluminação pública, praças ajardinadas, abertura de ruas largas (30 a 44 metros) com calçadas.

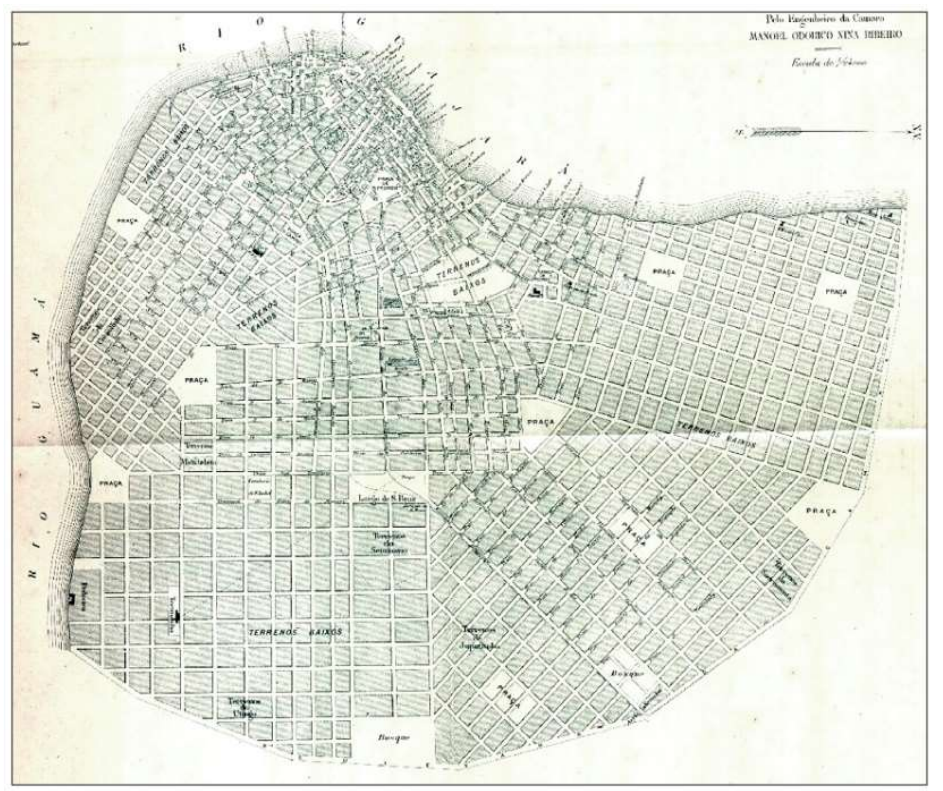

Figura 3 - Belém: Planta de Nina Ribeiro contendo a área de expansão.

Fonte: Muniz (1904)

Vale destacar que, durante a época da economia gomífera, a cidade de Belém progrediu substancialmente. Bairros como São Brás, Batista Campos e Nazaré foram os que mais cresceram. Os bairros da zona norte e sul eram os que continham o maior número de habitantes, e eram os mais pobres da cidade. O da Pedreira, por exemplo, estava próximo ao centro da cidade, mas revelava-se como um ambiente 
inóspito, com mal cheiro oriundo da água parada e do acúmulo do lixo despejado nos corpos hídricos lá existentes (PIMENTEL et al., 2012).

Após a década de 1930, políticas públicas com o objetivo valorizar o centro da cidade de Belém foram instituídas. Para melhoria da infraestrutura, foram realizadas obras de saneamento, como a canalização e o aterramento de "baixadas". A população pobre moradora destas áreas alagáveis vivia em situações precárias e foi remanejada para locais distantes, fora da primeira légua patrimonial, para bairros periféricos em relação ao centro (PIMENTEL et al., 2012).

Após o aterramento de igarapés localizados nas proximidades do centro, aumentou a demanda por imóveis de melhor padrão construtivo e pela pavimentação de vias. Algumas áreas foram favorecidas, em detrimento das demais, e atraíram a classe média e alta. O bairro da Pedreira passou a ter características modestas, grandes casarões e ruas largas. A Avenida Pedro Miranda, uma das principais vias do bairro, demonstra o estilo de vida superior à de outros bairros de Belém (Figura 4) (PENTEADO, 1968).
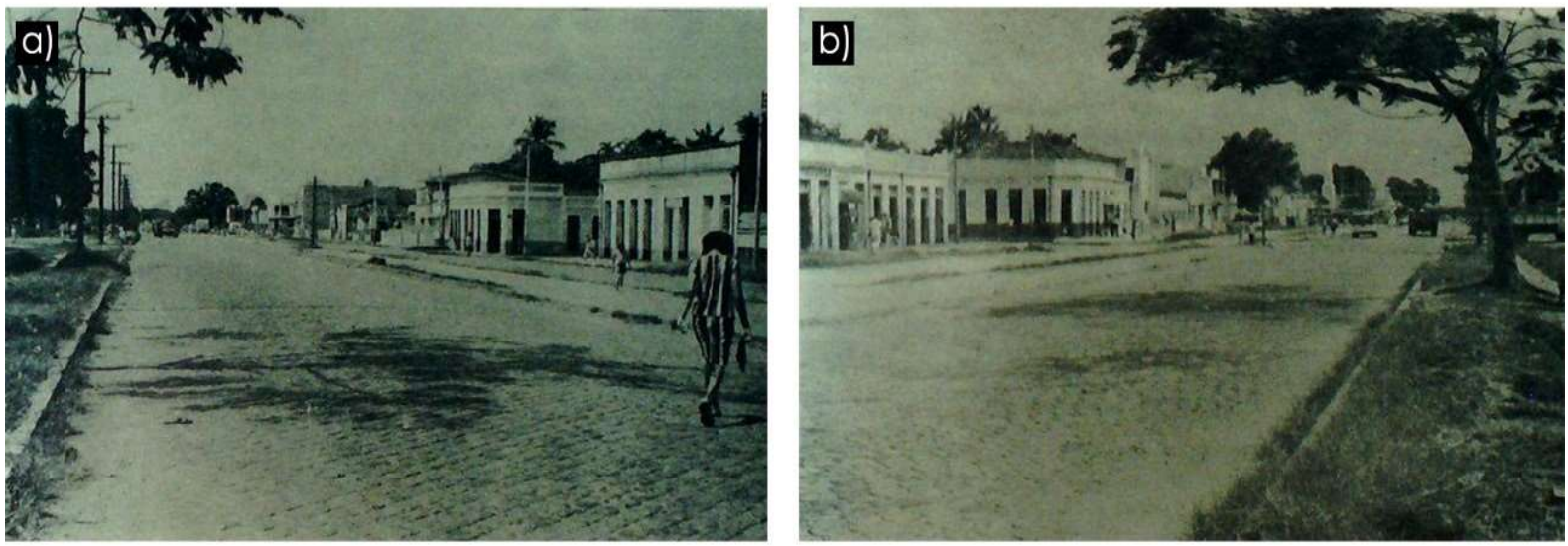

Figura 4 - Aspectos físicos urbanos do Bairro da Pedreira nos anos Fonte: Penteado (1968).

Na medida em que intensificava a urbanização na localidade, a realidade do bairro passava a se diferenciar da anterior. Atualmente, o bairro da Pedreira é intensamente ocupado, possui área equivalente a 3,74km² e população estimada em 69.608 habitantes pelo Censo Demográfico de 2010, (IBGE, 2011), sendo $54,13 \%$ composto por mulheres (BELÉM, 2019). A morfologia urbana do bairro, mistura ocupações formais e informais sobre uma área que tem em seus principais corredores viários o uso predominantemente comercial. As, com edificações muito próximas, que em alguns momentos compartilham a mesma estrutura física, estas representam cerca de 90,04\% de sua extensão territorial.

Segundo dados do IBGE em 2010, havia 19.003 domicílios particulares permanentes no bairro da Pedreira, dos quais $84,36 \%$ eram atendidos com rede geral de abastecimento de água e $15,36 \%$ por poço ou nascente na propriedade (BELÉM, 2019).

\section{Impactos do crescimento urbano no bairro da Pedreira - Belém-PA}

\section{Impermeabilização do solo}

A impermeabilização do solo, descrita pela Comissão Europeia (2013) como "cobertura permanente de uma dada superfície de terreno e de seu solo com materiais artificiais impermeáveis, como asfalto e 
cimento", é uma modificação da paisagem natural atribuída, principalmente, à urbanização, podendo ser considerada um dos principais processos de degradação do solo.

Dos $3,74 \mathrm{~km}^{2}$ da área total do bairro, cerca de $55 \%$ são compostos por área impermeável, ou seja, edifícios residenciais, comerciais, pavimentação asfáltica, enquanto $45 \%$ são constituídos de áreas verdes e permeáveis (Figura 5). A presença de vegetação no bairro estudado é baixa, pois a maioria destes são áreas de vegetação são rasteira, sem cuidado e abandonadas, sendo estas na maioria terrenos baldios e área de mato alto em torno dos canais, mesmo nas áreas públicas.

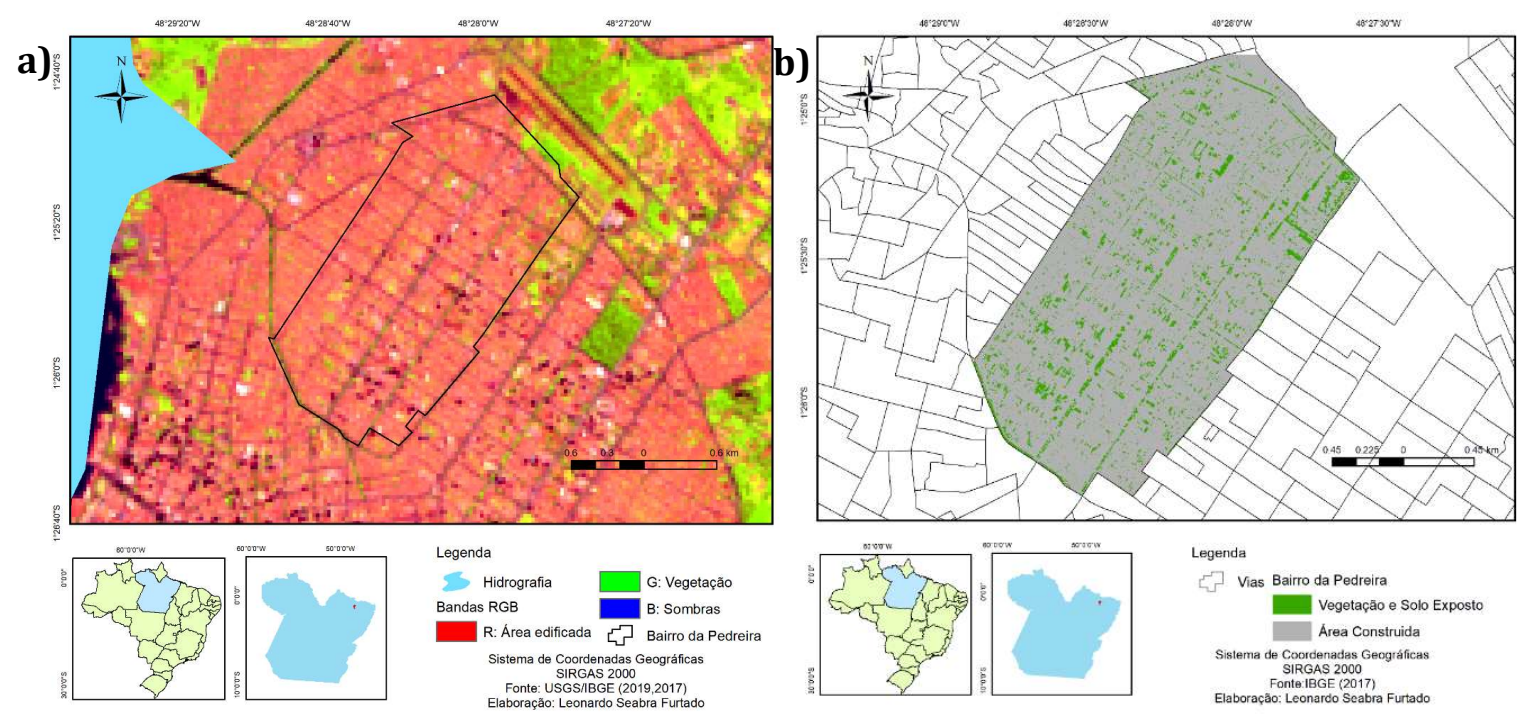

Figura 5 - Bairro da Pedreira: áreas verdes e áreas edificadas. Legenda: a) Visão elaborada a partir de elevação de contraste no software Spring em Bandas RGB; b) Visão elaborada com base em imagem obtida na plataforma do Google Earth. Fontes: USGS (2019) e Google Earth (2019), adaptados pelos autores.

O processo de impermeabilização do solo resulta na redução da filtragem da água, trazendo como consequência o aumento da vazão hídrica para regiões de cotas altimétricas mais baixas. No bairro da Pedreira, a impermeabilização vem gerando o escoamento de maior fluxo de água para próximo à Travessa Antônio Baena e para Canal do Galo, grandes áreas alagadas, provocando problemas de redução da mobilidade urbana, como de formação de sítios de propagação de doenças. A falta de rigor na aplicação das diretrizes de planejamento urbano e dos índices urbanísticos, notadamente no que diz respeito à permeabilidade do solo, tem sido generalizada em Belém e outras cidades da região amazônica.

A Comissão Europeia de Meio Ambiente - CEMA (2003) lembra que "combater a impermeabilização do solo significa também combater a ocupação do solo". Isso não significa frear o desenvolvimento urbano ou mesmo inibir a utilização do solo, mas sim regular a ocupação de modo a garantir a utilização eficiente e sustentável dos recursos disponíveis.

Junto à limitação da impermeabilização algumas soluções poderiam ser adotadas para atenuar a pressão exercida pelo "concreto". Como exemplo, a CEMA (2003) sugere o arrendamento de imóveis desocupados para a implantação de infraestrutura verde, o que possibilitaria a redução das ilhas térmicas, a elevação do contingente de absorção pluviométrica (aliviando o sistema de escoamento), além de fornecer espaço recreativo à população. Outra solução seria a utilização de revestimentos de piso com materiais de superfície permeável, que favoreça o escoamento das águas pluviométricas, o que minimiza, 
substancialmente, a ocorrência e a intensidade das enchentes e alagamentos, além de contribuir para a recarga dos aquíferos (COMISSÃO EUROPEIA, 2013; MONTEIRO, 2010).

\section{Acúmulo de resíduos e entulhos}

A exposição do lixo e entulhos reflete duas problemáticas principais: educação ambiental efetiva na e da população; e, planejamento do poder público. A promoção de atividades e capacitações dos moradores em educação ambiental é apontada como uma importante estratégia para a redução dos impactos gerados pelos resíduos urbanos. Além disso, é recomendada a distribuição suficiente de caçambas do tipo "Dempler" nas ruas ou áreas específicas da cidade, onde notoriamente há adensamento populacional ou padrão de consumo elevado. A troca de resíduos por redução de impostos, também, seria uma estratégia para a minimização dos impactos dos resíduos no meio urbano.

A coleta de lixo e a presença de lixeiras comunitárias, em várias áreas de Belém, é deficiente. Como resultado se observam diversos pontos de acúmulo de resíduos domésticos e entulhos, sem acondicionamento correto. Tal comportamento além de promover uma poluição visual, representa um foco de propagação de doenças como verificado por Santos et al. (2008).

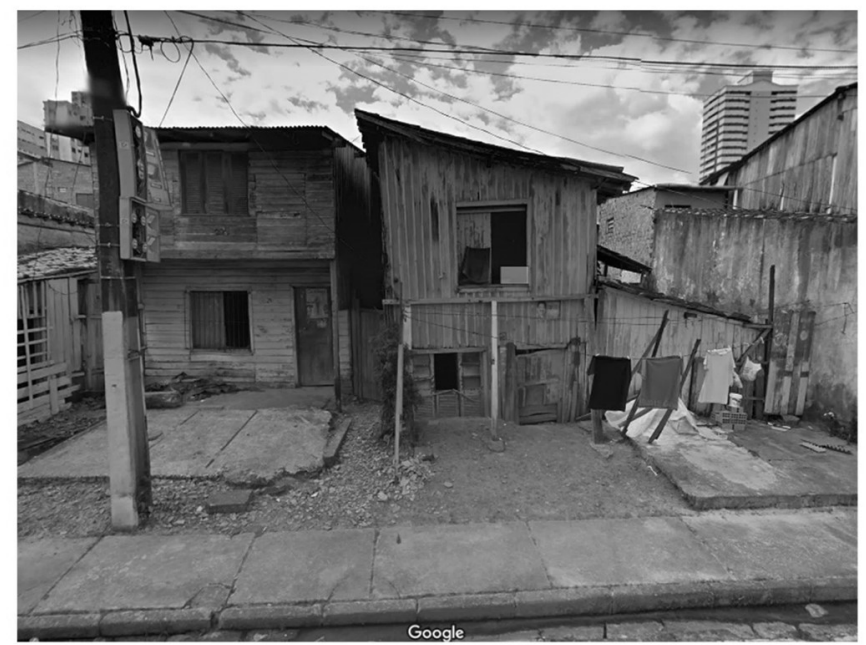

Figura 6 - Moradias informais situadas na Travessa Antônio Baena, Pedreira, Belém/PA Fonte: Google Maps - Street View (2019).

Isso se verifica em vários locais do bairro da Pedreira, sobretudo nas áreas de ocupações informais e irregular. Estas áreas estão presentes em quase toda a poligonal do bairro, porém se concentram, com maior intensidade, em torno dos canais de drenagem a céu aberto (Figura 6). As residências aí localizadas são predominantemente de madeira, e geralmente não dispõem de instalações de saneamento básico, como água canalizada e rede de esgotamento sanitário. Além disso, resíduos sólidos - inclusive de grandes dimensões, como móveis e eletrodomésticos deteriorados - são descartados pela população diretamente ou nas margens da rede de canais, sem qualquer controle e destinação ideal (Figura 7). 

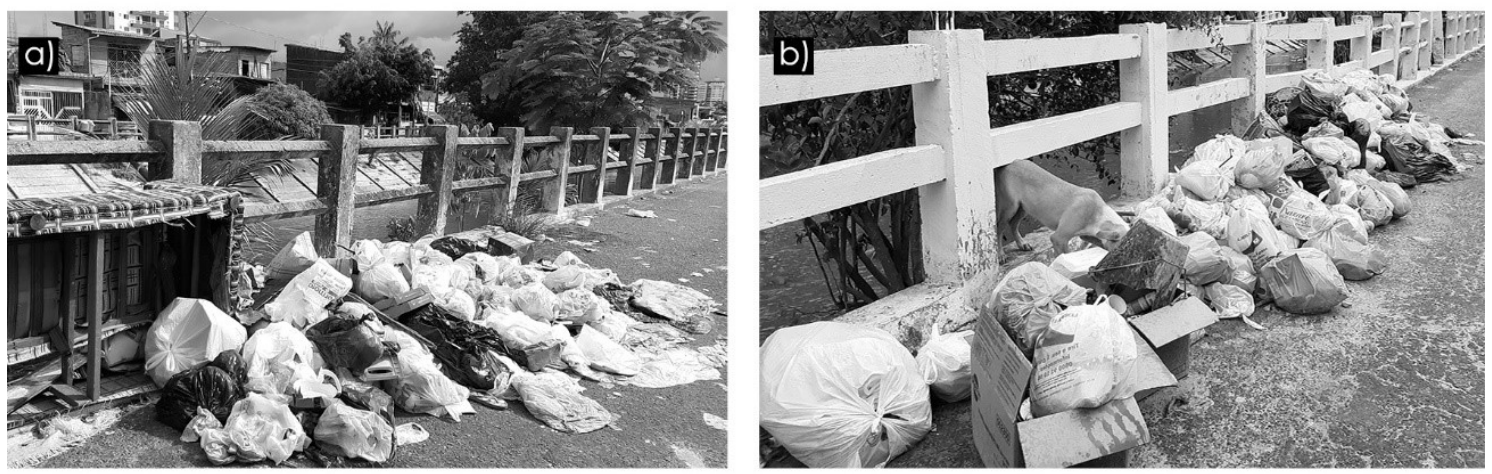

Figura 7 - Acúmulo de lixo ao longo da Avenida Visconde de Inhaúma, Pedreira, Belém/PA.

Guimarães et al. (2017) alertam para o fato de que os acúmulos de resíduos sólidos, sem tratamento e destinação correta, são vias de contaminação hídrica e do solo local. Mucelin et al. (2008), em estudos sobre os impactos ambientais gerados por resíduos urbanos, retratam que, o descarte incorreto, efetuado diariamente pela população, faz com que os moradores locais passem a considerar essa prática como normal, sem correlacioná-la com os riscos e danos que promovem à saúde e ao meio ambiente. $\mathrm{O}$ hábito consumista da sociedade, estimulado pela própria lógica de funcionamento do capitalismo, por outro lado, gera uma elevada e crescente produção de resíduos, provocando não apenas alterações no espaço urbano, como colaborando para transformações no cenário ambiental global, à exemplo das mudanças climáticas (SATTERTHWAITE, 2009).

\section{Poluição visual}

Segundo alguns estudos, o cérebro humano quando exposto a situações visuais menos complexas revela facilidade em entender a paisagem ao seu redor. Já as informações tidas como complexas com detalhes exagerados e desordenados, como cores, formas e muitos textos, provocam confusão na compreensão das mensagens, podendo causar estresse mental (CANDIDO et al., 2016).

No do bairro da Pedreira, o comércio popular, com estabelecimentos dos mais variados tipos e tamanhos, especialmente nas vias intensamente movimentadas, são os principais responsáveis pela poluição visual, na medida em que instalam objetos de diferentes dimensões, tipos e cores, que, não raras vezes, desrespeitam a regulamentação municipal de publicidade em espaços públicos (Figura 8).
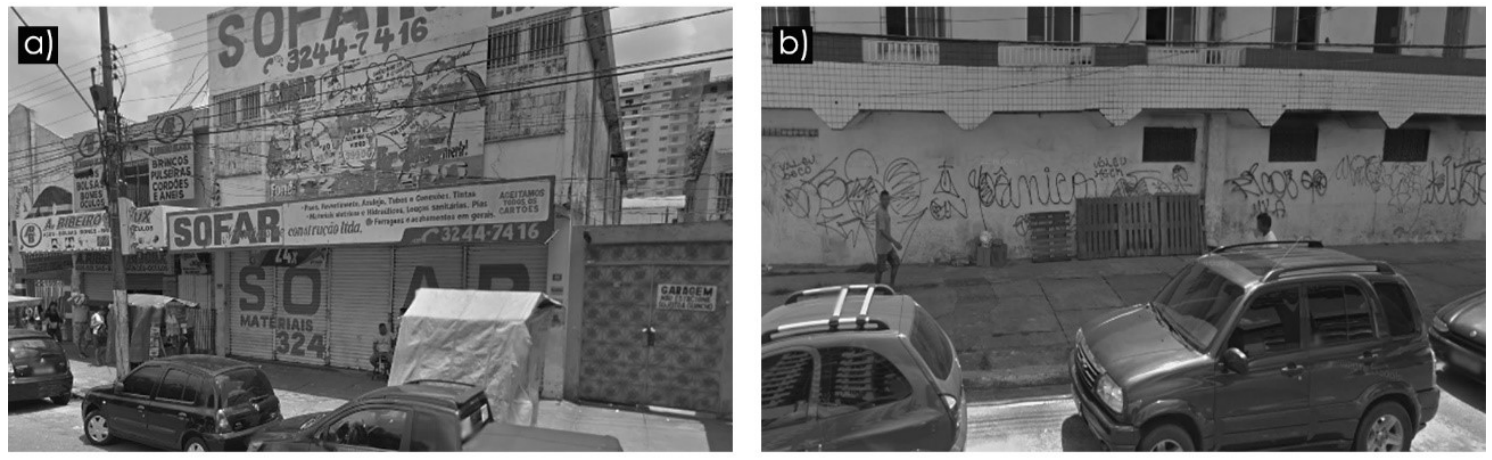

Figura 8 - Poluição visual por publicidade em fachadas de lojas e pichação de paredes ao longo da Avenida Pedro Miranda, Pedreira, Belém/PA. Fonte: Google Street View 
Vale destacar que a poluição visual não é somente aquela devida às propagandas impressas, pintadas em cartazes, outdoors, faixadas de lojas. Para Júnior (2002), ela envolve, também, o conjunto de artifícios que afetam a visibilidade do homem. Assim, o autor insere como poluição visual, também, as ocupações irregulares, o lixo nas ruas, as pichações, dentre outras.

A definição do que constitui poluição visual nem sempre é fácil, pois depende, em muitos casos, da cultura e dos valores estéticos de cada sociedade. Mas, uma vez estabelecido isso, ela deve ser controlada. Além disso, a maioria dos problemas de poluição visual existente no bairro - tanto no que concerne à aglomeração e sobreposição de placas, cartazes, faixas e pinturas, quanto aqueles decorrentes do desrespeito ao código de posturas - seriam minimizados se o cumprimento da legislação municipal fosse observado.

A aplicação de soluções é possível, a partir do momento em que haja conscientização da população e fiscalização pelos órgãos ambientais e de controle urbano do poder público e da sociedade civil. A atuação junto com a população para difundir o conhecimento sobre a poluição visual e seus danos, nesse sentido é fundamental (PIQUEIRA, 2007).

\section{Redução das Áreas Verdes}

Para Copque et al. (2011), a expansão e o desenvolvimento acelerados dos centros urbanos ocorreram sem planejamento que articulasse a necessidade de moradia a de espaços coletivos com a manutenção de áreas verdes, o que fez com que houvesse forte redução desses espaços. Essa situação pode ser notada no bairro da Pedreira, onde a retirada de áreas verdes para a expansão de usos residencial e comercial, vem ocasionando o aumento de temperatura local.

Algumas das soluções para o os efeitos no clima da redução da cobertura vegetal são: a criação de parques; o aumento de áreas permeáveis do solo; a instalação e telhados verdes e/ou de jardins verticais, especialmente em grandes prédios; e a educação ambiental destinada a conscientizar e sensibilizar a população sobre a importância dos espaços verdes em meio ao bairro.

\section{Poluição Sonora}

Segundo Musafir (2014), poluição sonora é qualquer alteração das propriedades de ruído do meio ambiente, gerada direta ou indiretamente por ação antrópica, que impeça ou dificulte a utilização funcional do ambiente ou que possa causar prejuízos auditivos para as pessoas moradoras ou visitantes daquele local.

No bairro da Pedreira ao comercio, nas vias onde há grande concentração de atividades terciárias, observa-se, junto à poluição visual, também a poluição sonora afetando a qualidade de vida urbana. Medições da taxa Leq (nível de ruído equivalente) em locais com maior movimentação de veículos e pedestres (áreas comerciais), mostraram que nos horários entre 14 e 16 horas, a taxas de ruído variam entre os $63 \mathrm{~dB}$ e $80 \mathrm{~dB}$. Em pontos mais afastados, como na esquina da Travessa Antônio Baena com Marques de Herval, a taxa de ruído ficou próximo aos $56 \mathrm{~dB}$ e na esquina da Avenida Dr. Freitas com Visconde de Inhaúma 
apresenta a taxa de ruídos próxima a 59dB. È de se ressaltar que, conforme a Organização Mundial da Saúde (1999), ruídos acima de 65dB são danosos a saúde humana.

Com base nesses dados, pode-se inferir que as soluções visando à redução da poluição sonora, no caso do bairro estudado, estão centradas pelo menos em dois pontos específicos: o controle da quantidade de ruídos emitidos pelos estabelecimentos comerciais e serviços sonoros de propaganda do bairro; e, a melhoria da qualidade acústica das edificações situadas nas proximidades dos locais de maior movimentação do bairro, visto que sem o isolamento correto, os ruídos tendem a entrar nas edificações de forma mais fácil e circular internamente no espaço (DELFINA, 2013).

\section{CONSIDERAÇÕES FINAIS}

A intensificação da urbanização e o crescimento demográfico em áreas urbanas vem suscitando muitas discussões sobre os impactos ambientais que tem provocado. No Brasil, o desenvolvimento industrial tardio estimulou o êxodo da população rural que migrou para as cidades em busca por melhores oportunidades de trabalho e condições vida, elevando o contingente demográfico nas áreas urbanas, sem que isso fosse acompanhado, no mesmo ritmo, pela provisão de moradias e infraestruturas adequadas. Na Amazônia, o processo urbano que era relativamente contido e seguia o padrão rio-várzea-floresta, a partir da década de 1960, se modifica e intensifica, com a abertura de rodovias e o estímulo governamental a instalação de grandes projetos econômicos na Amazônia.

Belém, capital do Pará, que havia sido a principal metrópole regional, foi amplamente impactada, passando a receber grande fluxo de população de cidades interioranas que tiveram sua economia impactada pela concorrência com produtos de outras regiões e que não receberam os incentivos e investimentos federais. Assim, as periferias da cidade cresceram extremamente rápido e de forma desorganizada.

O Bairro da Pedreira, hoje localizado entre o centro de ocupação inicial e a periferia urbana, apresenta particularidades desde a década de 1930, quando começaram a ser implantadas melhorias relacionadas à infraestrutura. Com o crescimento da malha urbana, o bairro se tornou uma área bastante valorizada pelo mercado imobiliário para construção de comércios e moradias.

A retirada maciça e desordenada de áreas verdes, a substituição do solo natural por pavimentação impermeável (asfáltica e concreto), o avanço do mercado imobiliário em direção aos lotes vazios remanescente do bairro - e que poderiam ser revitalizados, com arborização de qualidade e destinados para o lazer, a degradação ambiental decorrente das deficiências na infraestrutura de saneamento básico, as poluições visual e sonora, e o desconforto ambiental potencializado pelas mudanças no microclima local são alguns dos impactos identificados no presente trabalho. Esse quadro vem sendo agravado porque o crescimento populacional e o avanço do capitalismo vêm provocando a mudança nos padrões de consumo, aumentando a aquisição de itens supérfluos e, consequentemente, a produção e o descarte de rejeitos e resíduos em áreas urbanas.

Sem planejamento adequado e despreparado para lidar com os efeitos da urbanização o meio ambiente, os moradores, trabalhadores e usuários do bairro da Pedreira são os principais prejudicados, já 
que os alagamentos intensificados pela impermeabilização do solo, o lixo despejado de maneira inapropriada, maximizando a propagação de doenças, as poluições visual e sonora, a escassez de arborização e áreas verdes, dentre os outros problemas aqui identificados interferem diretamente na qualidade de vida dos moradores do bairro.

Por fim, são diversos os problemas ambientais existentes em um bairro ou uma cidade. $\mathrm{O}$ enfrentamento deles não depende apenas de atitudes públicas, a educação ambiental, o bom senso e a participação da população também podem influenciar, diretamente, na escala em que ocorrem, assim como na solução dos mesmos.

\section{REFERÊNCIAS}

ALVES, E. R. A.; SOUSA, G. S.; MARRA, R.. Êxodo e sua contribuição à urbanização de 1950 a 2010. Revista de política agrícola, v.20, n.2, p.80-88, 2011.

BRASIL. Lei n. 6.938, de 31 de agosto de 1981. Dispõe sobre a política Nacional do Meio Ambiente, seus fins e mecanismos de formulação e aplicação, e dá outras providências. Brasília: DOU, 1981.

BRASIL. Constituição da República Federativa do Brasil, Artigo 225. Brasília: DOU, 1988.

BRITO, F.; HORTA, C. J. G.; AMARAL, E. F. L.. A urbanização recente no Brasil e as aglomerações metropolitanas. Open Science Framework Preprints, 2018. DOI: http://doi.org/10.31219/osf.io/84b92

CANDIDO, C. R.; DOMINGOS, R. M. A.; SANCHES, J. C. M. Poluição visual: estudo da qualidade visual da cidade de Sinop, MT. In: CONGRESSO LUSO BRASILEIRO PARA O PLANEJAMENTO URBANO, REGIONAL, INTEGRADO E SUSTENTAVEL - PLURIS, 7. Anais. Maceió, 2016.

CARDOSO, A. C. D.; FERNANDES, D. A.; BASTOS, A. P. V. (2015). A inserção da RMB na Amazônia e na rede urbana brasileira. In: CARDOSO, A. C. D.; FERREIRA J. J. L.. Belém: transformações na ordem urbana. Rio de Janeiro: Letra capital, 2015. p.33-58.

CARLOS, A. F.. Espaço-Tempo na Metrópole. São Paulo: Contexto, 2001

CHAVES, T. A. P. V.. O plano de urbanização de Belém: cidade e urbanismo na década de 1940. Tese (Doutorado) Universidade Federal do Pará, Belém, 2016.

COELHO, M. C. N.. Impactos ambientais em áreas urbanas: teorias, conceitos e métodos de pesquisa. In: GUERRA, A. J. T.; CUNHA, S. B.. Impactos ambientais urbanos no Brasil. Rio de Janeiro: Bertrand Brasil, 2001.

COIMBRA, D.; RIGO, K. B.. O papel do Direito no planejamento urbano para a biodiversidade $\mathrm{In}$ : INSTRUMENTOS JURÍDICOS DE POLÍTICAS AMBIENTAIS SUSTENTÁVEIS, 126. Anais. 2019.

COMISSÃO EUROPEIA. Direção geral do Ambiente. Orientações sobre as melhores práticas para limitar, atenuar ou compensar a impermeabilização dos solos.
Comissão Europeia, 2013. DOI: https://doi.org/102779/88588

COPQUE, A. C. S. M.; SOUZA, F. A.; SANTOS, D. D. C.; PAIXÃO, R. D.. Expansão urbana e redução de áreas verdes na localidade do Cabula VI Região do miolo da cidade do Salvador, Bahia. In: SIMPÓSIO BRASILEIRO DE SENSORIAMENTO REMOTO-SBSR, 15. Anais. Curitiba, 2011. p.706-713.

COSTA, S. M. F.; CARMO, M. B. S.; BARJA, P. R.. The urban hierarchy at the delta of the Amazon River and the importance of small cities. Revista Brasileira de Gestão Urbana, v.11, n.e20180014, 2019. http://dx.doi.org/10.1590/2175-3369.011.001.ao09

DELFINA, C.. Soluções inovadoras para o conforto acústico em ambientes urbanos. Com Ciência, 2013.

DIAS, C. S.; DIAS, S. I. S.. Belém do Pará: história, urbanismo e identidade. Planejamento Urbano e Regional: ensaios acadêmicos do CAUFAG. Cascavel: Smolarek Arquitetura, 2007.

GOMES, M. A. S.; SOARES, B. R.. Reflexões sobre qualidade ambiental urbana. Estudos Geográficos: Revista Eletrônica de Geografia, v.2, n.2, p.21-30, 2004.

GOUVEIA, N.. Saúde e meio ambiente nas cidades: os desafios da saúde ambiental. Saúde e Sociedade, v.8, p.49$61,1999$.

GUIMARÃES, R. J. P. S. E. R.; CATETE, T.; ALVES, C. P.; SILVA, P. P. A.. Georreferenciamento dos pontos de alagamento em Belém (PA). In: CONGRESSO DA ABES/FENASAN. Anais. São Paulo: ABES, 2017

IBGE. Instituto Brasileiro de Geografia e Estatística. Sinopse preliminar do censo demográfico. Rio de Janeiro: IBGE, 2000.

IBGE. Instituto Brasileiro de Geografia e Estatística. Pesquisa nacional por amostra de domicílios. 2015. Rio de Janeiro: IBGE. Recuperado em 27 de outubro de 2019

IBGE. Instituto Brasileiro de Geografia e Estatística.

Tendências demográficas: uma análise da população com base nos resultados dos censos demográficos 1940 e 2000. Rio de Janeiro: IBGE, 2007. 
IBGE. Instituto Brasileiro de Geografia e Estatística. Censo de 2010. Rio de Janeiro: IBGE, 2010.

KAMPEL, S. A.; CÂMARA, G.; MONTEIRO, A. M. V.. Análise espacial do processo de urbanização da Amazônia. Programa de Ciências e Tecnologia para Gestão de Ecossistemas, Relatório técnico, Ministério da Ciência e Tecnologia, Instituto Nacional de Pesquisas Espaciais. Brasília: INPE, 2001.

KRZYSCZACK, F. R.. As diferentes concepções de meio ambiente e suas visões. Revista de Educação do IDEAU, v.11, n.23, p.1-17, 2016

LLARDENT, L. R-A.. Zonas verdes y espacios libres en la ciudad. Instituto de Estudios de Administración Local, 1982.

LOBODA, C. R.; ANGELIS, B. L. D.. Áreas verdes públicas urbanas: conceitos, usos e funções. Revista Ambiência, v.1, n.1, p.125-139, 2005.

MARICATO, E.. Brasil, cidades: alternativas para a crise urbana. Petrópolis: Vozes, 2001.

MAZZETO, F. A. P.. Qualidade de vida, qualidade ambiental e meio ambiente urbano: breve comparação de conceitos. Sociedade \& Natureza, v.12, n.24, 2014.

MENDONÇA, F.; MONTEIRO C. A. F.. Clima urbano. São Paulo: Contexto, 2002.

MINC, C.. A ecologia nos barrancos da cidade. In: VIANA, G.; SILVA, M.; DINIZ, N.. O desafio da sustentabilidade: Um debate socioambiental. São Paulo: Perseu Abramo, 2002.

MONTEIRO, A. C. N.. Concreto poroso: Dosagem e desempenho. Monografia (Bacharelado) - Universidade Federal de Goiás, Goiânia, 2010.

MOREIRA, E.. Belém e sua expressão geográfica. Belém: Imprensa universitária, 1966.

MUCELIN, C. A.; BELLINI, M.. Lixo e impactos ambientais perceptíveis no ecossistema urbano. Sociedade $\&$ Natureza, v.20, n.1, p.111-124, 2008. DOI: http://doi.org/10.1590/s1982-45132008000100008

MUSAFIR, R. E.. Poluição sonora. Rio de Janeiro: Documento de trabalho, 2014.

OMS. Organização Mundial da Saúde. Guidelines for Community Noise. Londres: OMS, 1999.

PAWAN, B.. Urbanization and Its Causes and Effects: a review. International Journal of Research and Scientific Innovation, v.3, n.9, p.110-112, 2016. http://doi.org/10.1038sdata.2016.34.ISSN

PENTEADO, A. R.. Belém: estudo de geografia urbana. 2 ed. Belém: UFPA, 1968.
PEREIRA JÚNIOR, J. S.. Legislação Federal Sobre 'Poluição Visual' Urbana. Brasília: Consultoria Legislativa da Câmara dos Deputados, 2002.

PIMENTEL, M. A. S.; SANTOS, V. C.; SILVA, F. A. O.. A ocupação das várzeas na cidade de Belém: causas e consequências socioambientais. Revista Geonorte, v.3, n.5, p.34-45, 2012

PIQUEIRA, G.. Cidade limpa. São Paulo: Rex Livros, 2007.

RIBEIRO, H.; VARGAS, H.. Urbanização, globalização e saúde. Revista USP, v.107, p.13-26, 2015. DOI: http://doi.org/10.11606/issn.2316-9036.v0i107p13-26

RIBEIRO, M. A. C.. A dimensão urbana da questão ambiental na Amazônia. Boletim Goiano de Geografia, v.16, n.1, p.83 99, 1996

SANTOS, G. O.; SILVA, L. F. F.. Os significados do lixo para os garis e catadores de Fortaleza (CE, Brasil). Ciência \& Amp.; Saúde Coletiva, v.16, n.8, p.3413-3419, 2008. DOI: http://doi.org/10.1590/S1413-81232011000900008

SANTOS, M.. Desenvolvimento econômico e urbanização em países subdesenvolvidos: os dois sistemas de fluxo da economia urbana e suas implicações espaciais. Boletim Paulista de Geografia, v.53, p.35-60, 1977.

SANTOS, M.. A urbanização brasileira. 5 ed. São Paulo: Universidade de São Paulo, 2005

SATTERTHWAITE, D.. The implications of population growth and urbanization for climate change. Environment and Urbanization, v.21, n.2, p.545-567, 2009.

SILVA, J. A. B.; BARROSO, R. C. A.; RODRIGUES, A. J.; COSTA S. S.; FONTANA, R. L. M.. Á Urbanização No Mundo Contemporâneo E Os Problemas Ambientais. Caderno de Graduação: Ciências Humanas e Sociais, v.2, n.2, p.197-207, 2014.

SOARES, K. G.. Como formas de morar na Belém da Belle Époque (1870-1910). Dissertação (Mestrado) - Universidade Federal do Pará, Belém, 2008.

SPOSITO, M. E. B.. Capitalismo e urbanização. Contexto, 1988.

TRINDADE JUNIOR, S-C. C.. A Amazônia oriental brasileira: processos de territorialização e perspectiva de fragmentação política do espaço. In: COLÓQUIO INTERNACIONAL DE GEOCRÍTICA, 12. Anais. Bogotá: Universidade Nacional da Colômbia, 2012

TRINDADE JUNIOR, S-C. C.. Grandes projetos, urbanização do território e metropolização na Amazônia. Revista Terra Livre, v.1, n.26, p.177-194, 2015.

VARGAS, H. C.. Espaço terciário: o lugar, a arquitetura e a imagem do comércio. São Paulo: SENAC, 2001.

A CBPC - Companhia Brasileira de Produção Científica (CNPJ: 11.221.422/0001-03) detém os direitos materiais desta publicação. Os direitos referem-se à publicação do trabalho em qualquer parte do mundo, incluindo os direitos às renovações, expansões e disseminaçães da contribuição, bem como outros direitos subsidiários. Todos os trabalhos publicados eletronicamente poderão posteriormente ser publicados em coletâneas impressas sob coordenação da Sustenere Publishing, da Companhia Brasileira de Produção Científica e seus parceiros autorizados. Os (as) autores (as) preservam os direitos autorais, mas não têm permissão para a publicação da contribuição em outro meio, impresso ou digital, em português ou em tradução. 